volume provides and so much is only to be found in scattered papers and communications. The various articles, some of which have been read before the Society, fill some gaps in our knowledge and will be of considerable interest and value to the geneticist, zoologist, anatomist and research worker. The various contributions, 15 in all, are well documented and include extensive references which should be of great use to research workers. It would be difficult and invidious to select for comment any individual contributions as much depends on the special aspects of the different subjects surveyed.

In the past, perhaps, there has been a tendency to accumulate unrelated and particular facts when the real object is to be aware of the nature of structure and action in the plan of life; to enquire into the reason for the existence of so many modifications, the forces producing such changes in animal forms and of the rhythms at work to bring about variations and 'even forecast how such rhythms are likely to operate in the future'.

Here, in these several articles, there is a sense of coherence, and interrelationship. The Editor and contributors are to be congratulated upon this work and the access to knowledge set down.

It is, moreover, satisfactory to learn that comparative orthodontic studies concerned with the teeth and jaws are being considered and it is to be hoped that more knowledge on this rather neglected and important subject will be forthcoming because such studies should be of much value to the orthodontist, and well worthy of furtherance.

\section{Trends in the Mental Health Services}

A Symposium edited by Hugh Freeman and JAMES Farndale. Pp. xv + 34I. Oxford, London, New York and Paris: Pergamon Press. 1963. 7os.

This book consists of a compilation of papers on various aspects of mental health services. The papers are grouped in three sections, dealing with psychiatric hospitals, day hospitals and community services respectively. In their preface the editors refer to '... subsequent volumes, following the present one as a series' but on the evidence of the present volume it is difficult to know for whom such a series is intended. Only about one-third of the articles are original; the remainder have been reprinted from various journals. The specialist reader will have ready access to most of the previously published material and is unlikely to be persuaded by the editors' argument that '.. . he may be spared some of the tedium of watching the publications of several continents and many disciplines', especially as eight of the papers have appeared in the Lancet or British Medical fournal in the past three years. He is still less likely to be persuaded by the quality of the articles: a handful are well-informed and to the point but too many are verbose expressions of personal, and often idiosyncratic, opinions. Perhaps there are many more non-specialist readers, undeterred by price and uncritical of content, whose interest in mental health services will lead them to purchase a book of this type. In that event we may look forward to a second volume in due course.

\section{Child Health and Development}

Edited by R. W. B. Ellis. Third edition. Pp. xi +485 , illustrated. London: J. \& A. Churchill. 1962. $56 s$.

The title and the meaning of this book grows in importance as the editions increase. This, the third, increases its own strength through its own nutrition. Each contributor puts fact, reason and philosophy into the chapters with the result that this book is a high-lipht in the sphere of medical education of a most enlighteñed order. Physiology and pathology, health and disease, emotional and physical growth, preventive aspects of mental health and the development of behaviour, indicate the scope. To emphasize that medicine is nowno longer to be considered an isolated or functionally $\underline{\underline{W}}$ related subject, Professor Ellis and his team of authors have gathered in this book enough to break down amount of initial inertia for the progress of the braad and deep concepts of health in all the stages of earlygife and the difficulties inherent in 'growing up' in this modern 'civilized' sophisticated world, where sense@of values are easily misconstrued and even the economics. of health and happiness are frequently sadly misunderstood. Any thoughtful and intelligent person could 㮲d substance with understanding in these chapters. Certainly no one who aspires to clinical pædiafic practice or to the higher appreciation of principlespin education and health education could possibly afford to omit this book from their library list. Part I ofn Development is a classic indeed-a near perfect cơnbination of the known factors in growth, maturation and mental development. The integrative influences for good contained in the statutory and the voluntary services of our nation are elaborately outlined in PartII - Social Aspects of Child Health-in which such iterns as care of the Under-Privileged Child; Vocatioffal Guidance; The Aims and Problems of Education; Juvenile Courts; are sensibly and pleasantly discussd. The chapter on Child Health in the Tropics is mest helpful indeed and brings the book nearer to a gobal outlook. The synopsis of Legislation is also very ful, particularly now that awareness of the staturesfis essential knowledge for any doctor as well as a help in finding ways and means of coping with the many social, educational or psychological problems whish may present in day-to-day family practice or in hosptital or school. The book continues, therefore, as high-chss medical literature. My only criticism is that Geraldome $\mathrm{S}$. Cadbury's (1865-194I) name does not appear in the chapter on Juvenile Courts-she started the first Co $\overline{3}$ in Birmingham-initially on an illegal basis !

\section{Handbook of Operative Urological Surgery}

John Swinney and D. P. HAMmersley. Pp. viiof 271, illustrated. Edinburgh and London: E. \& Livingstone. 1963. $55^{s}$.

\section{Transurethral Prostatic Surgery}

Kyril B. Conger, M.D., F.A.c.s. Pp. $x+1 \frac{14}{30}$ illustrated. London: Baillière, Tindall \& Cox. 19\$3. $72 s$.

Every surgeon is as interested to look at a book $\frac{D}{\text { nn }}$ operative surgery, as he is to see a colleague perform operation, however familiar it may be. His interest particularly in details of technique, the main steps being well known. The serious reader of these books, however, is surely the postgraduate student, who is anxious learn the repertoire of operations which he will fhe called upon to perform in his practice and which he not had the good fortune to learn at first hand fror a master. It follows that a book on operative surgefy must be judged by the clarity of the picture whichenit imparts and its success in guiding the apprentice through the problems and hazards of operations. Many classigal texts cover such a vast field of practice that they can in fact do little more than sketch an outline of the jop, 